\title{
Engineering Futures: Updating a Successful Professional Development Pro- gram to Address New Challenges
}

\section{Dr. Katy Luchini-Colbry, Michigan State University}

Katy Luchini-Colbry is the Assistant Dean for Graduate Student Services at the College of Engineering at Michigan State University, where she completed degrees in political theory and computer science. A recipient of a NSF Graduate Research Fellowship, she earned Ph.D. and M.S.E. in computer science and engineering from the University of Michigan. She has published more than two dozen peer-reviewed works related to her interests in educational technology and enhancing undergraduate education through hands-on learning. Luchini-Colbry is also the Director of the Engineering Futures Program of Tau Beta $\mathrm{Pi}$, the Engineering Honor Society, which provides interactive seminars on interpersonal communications and problem solving skills for engineering students across the U.S.

\section{Dr. Christopher McComb, Pennsylvania State University, University Park}

Christopher McComb is an Assistant Professor in the School of Engineering Design, Technology, and Professional Programs with courtesy appointments in the Department of Mechanical and Nuclear Engineering and the Department of Industrial and Manufacturing Engineering. He earned dual B.S. degrees in Civil and Mechanical Engineering from California State University Fresno as well as M.S. and Ph.D. degrees in Mechanical Engineering from Carnegie Mellon University. His research merges perspectives from psychology, computer science, and engineering design to create better human systems. This includes both systems of humans (teams, organizations, marketplaces) as well as systems that interact with humans (intelligent design tools, smart products).

\section{Julie Rojewski, Michigan State University}

Julie Rojewski is the Program Manager of the Michigan State University Broadening Experience in Scientific Training (BEST) grant (funded by NIH). Previously, she was the Director of the MSU ADVANCE grant (funded by NSF), and has worked in several dimensions of graduate student and faculty development around teaching, mentoring, leadership, communications, and teamwork. She has a particular professional expertise with program planning, management, and evaluation and an academic interest in leadership development in academic contexts. She holds a M.A. in Education from Michigan State University and an M.A. in English from The Ohio State University.

\section{Mrs. Astri Briliyanti, Michigan State University}

Astri is a graduate student in the Department of Community Sustainability, Michigan State University. She previously worked as a researcher and urban planner consultant in Indonesia, helping the government with the creation of spatial and development plan, as well as policy analysis and program evaluation. She is interested in program evaluation, sustainable tourism planning, and urban design.

\section{Dr. Dirk Joel-Luchini Colbry, Michigan State University}

Dr. Dirk Colbry is the Director of HPC Studies in the newly formed Department of Computational Mathematics, Science and Engineering (CMSE) at Michigan State University. Dr. Colbry earned his Ph.D. in Computer Science and his principle areas of research include machine vision and pattern recognition (specializing in scientific imaging). Dr. Colbry also conducts research in computational education and high performance computing. From 2009 until 2015, Dr. Colbry worked for the Institute for Cyber-Enabled Research (iCER) as a computational consultant and Director of the HPCC. Dr. Colbry collaborates with scientists from multiple disciplines including Engineering, Toxicology, Plant and Soil Sciences, Zoology, Mathematics, Statistics and Biology. Recent projects include research in Image Phenomics; developing a commercially-viable large scale, cloud based image pathology tool; and helping develop methods for measuring the Carbon stored inside of soil. Dr. Colbry has taught a range of courses, including; communication "soft" skills, tools for computational modeling, Numerical Linear Algebra, microprocessors, artificial intelligence, scientific image analysis, compilers, exascale programing, and courses in program and algorithm analysis. 


\title{
Engineering Futures: Updating a Successful Professional Development Program to Address New Challenges
}

\begin{abstract}
Engineering Futures (EF) is a professional development program developed by Tau Beta Pi, the Engineering Honor Society, in the 1980s to provide undergraduate engineering students with the "soft skills" necessary for professional success. Originally, the EF program included a series of day-long, interactive workshops led by volunteer facilitators and hosted on-site at college campuses. The original sessions included People Skills (interpersonal problem communication and resolution); Team Chartering (understanding team dynamics); Group Process (tools for effective meetings); and Analytical Problem Solving (brainstorming, list reduction and evaluation criteria). Over the decades, the EF program adapted to meet the changing needs of undergraduate students, with options for shorter sessions and the addition of a module on Effective Presentation Skills in the early 2000s.
\end{abstract}

In the 2010s, the EF program directors began to explore opportunities to expand the curriculum to address new challenges. A new partnership in 2015 led to the addition of two new modules: Equity, Inclusion \& Engineering Ethics; and Research Mentoring. In 2017, Tau Beta Pi partnered with several other organizations in a successful proposal to the National Science Foundation to develop updated training materials focusing on communications, teamwork and leadership skills. These materials are being designed in a modular fashion that allows them to be adjusted for different audiences (undergraduates, graduate students, professionals) and the project includes funding for a "train the trainers" program that will enable the EF materials to be deployed nationally at little or no cost to hosting organizations.

This paper provides a historical context for the EF program, describes the recent efforts to update and expand the curriculum, and provides insights from several years of participation and program evaluation data.

\section{Introduction}

Strong, collaborative leadership methods can increase innovation [1], improve productivity [2], and leverage diverse perspectives, particularly in globally competitive contexts [3]. Yet despite calls from the National Academy of Engineering to increase professional skills training in engineering curricula [4], leadership training from other disciplines has not been particularly effective in building a leadership identity amongst engineers [5]-[7]. Customizing professional skills training to address challenges and develop leadership skills in the context of engineering can be very effective, however [8]-[10].

This paper describes efforts by the Tau Beta Pi Association, the Engineering Honor Society, to develop and deliver professional skills training to engineering students and professionals through the Engineering Futures (EF) program. Tau Beta Pi (TBP) was founded in 1885 "to mark in a fitting manner those who have conferred honor upon their Alma Mater by distinguished 
scholarship and exemplary character as students in engineering, or by their attainments as alumni in the field of engineering, and to foster a spirit of liberal culture in engineering colleges" [11]. There are nearly 300 active TBP chapters on college campuses and for alumni in 16 regional districts across the United States; the EF program provides free professional development training for approximately 4,000 engineering students and professionals each year.

\section{History of the Engineering Futures Program}

In the 1980s, Tau Beta Pi began to formalize training programs that had previously been offered ad hoc to students and professionals who volunteered to help lead the Association's collegiate chapters. Initially, these trainings were offered as "Chapter Operations Seminars" at the annual TBP Convention, later evolving into the current Interactive Chapter Exchange (ICE) program. After refining the training at the annual Convention, TBP started offering chapter leadership seminars at various campuses and locations around the country. This series of seminars for student leaders of campus chapters evolved and transformed into the Engineering Futures (EF) program [12].

In this midst of this development process, the Tau Beta Pi Association conducted a survey of alumni donors to ascertain the value of TBP membership in their careers, and specifically why they chose to continue to donate to the Association each year. Part of the survey introduced these alumni to the EF program, and their response was strong: training students to fill leadership roles was highly valuable and the EF program was a way for Tau Beta Pi to be of ongoing service to the engineering profession. EF also provided an opportunity for engineering professionals to remain engaged in the Association after graduation: alumni were recruited and trained to facilitate EF sessions on college campuses, which had the dual benefits of providing ongoing professional training for alumni and allowing students to benefit from the experiences of professional engineers.

As demand for EF trainings increased, the Association partnered with Dr. Kerry Patterson in order to develop an interpersonal skills training program for students that also integrated facilitator training into the process. Patterson is now well-known as an author of "Crucial Conversations" [13], but in the 1980s he was developing a company that used videos to provide training during facilitated seminars on interpersonal skills. These videos and training materials were adapted for the Association's engineering student audience and donated for use in the Engineering Futures program.

The initial EF curriculum covered four areas: People Skills, which focuses on communicating interpersonal problems; Team Chartering, which covers team dynamics and skills; Group Process, which offers tools for managing meetings effectively; and Analytical Problem Solving, which explores brainstorming and list reduction techniques as applied to technical challenges. These trainings were offered at college campuses across the nation to thousands of students over three decades, and were incorporated into for-credit engineering curricula at institutions like The Ohio State University and Purdue University. Engineering Futures became a key outreach and service program of the Association, because, as one of the first EF program facilitators noted, 
[T] he best engineers are those who can integrate their technical skills with an understanding of arts and humanities, or who can build and mentor a team of individuals who think and work differently, but who are united in pursuit of a common goal. Learning to communicate with people, work effectively in teams, and creatively solve problems is the core of Engineering Futures, and in developing this program Tau Beta Pi continues to invest in students and alumni who will embody the [Association's key] principle of "Excellence in Engineering. - Dr. John R. Luchini [12]

As demand for Engineering Futures increased, the Association sought input from alumni and student members in the mid-2000s to identify topics for additional training. A session on Effective Presentation Skills was developed in response to this input and to a rise in the perceived value of such training [14]. This new session was tested and refined over several years, becoming widely available by about 2010 . While prior trainings had been restricted to student participants due to agreements with the original content developer, this new module on presentations was available to alumni and was even adapted by some facilitators for use at their workplace or to benefit local non-profit organizations. Like all Engineering Futures sessions, these trainings are offered at little or no cost to participants and Tau Beta Pi covers travel expenses for volunteer facilitators, who donate their time to make these trainings available to engineering students and professionals.

\section{Identifying Challenges}

In 2015, three decades after the EF program emerged from chapter operations training programs, a new Director of Engineering Futures (DEF) was appointed by the Association. The new DEF was charged with assessing the current status of the EF program and developing short- and longterm plans to ensure its continued success. The DEF is an unpaid, volunteer role with responsibility for managing the annual program budget, recruiting and training volunteer facilitators, overseeing the fulfillment of training session requests, and evaluating and improving the curriculum. During the 2015-16 academic year, the DEF spoke with the volunteer facilitators at length and conducted an "asynchronous brainstorming session" online in order to gather input on curriculum content, session scheduling logistics, and ways to improve the EF program.

Based on this feedback, along with a review of financial and participation records, the DEF identified the following challenges to the Engineering Futures program's continued success:

- EF materials are designed for groups of $15-25$ participants, but $61 \%$ of all sessions over the previous four years had been provided to groups of 15 or fewer participants.

- A small group of facilitators ( $25 \%$ or fewer) typically facilitate the majority of sessions.

- It typically takes several years to be fully trained and ready to "solo" facilitate all sessions.

- Current program expectations are not well-aligned with the interests and availability of many experienced facilitators, thus we tend to lose volunteers just as they are fully trained.

- There are few ongoing development activities or team-teaching opportunities for facilitators. 
- The current session request, scheduling, and reporting processes are labor-intensive (both for volunteers and staff) and do not capture session data in a format that is useful for analysis.

- While the current materials generally work, they are showing signs of age and will need to be fully replaced in the next 2-5 years. There was significant discussion about the topics and types of sessions (online, in-person, hybrid, etc.) that can best meet the professional development needs of engineers, with no clear consensus among facilitators of the best path forward.

These data gathered during 2015-16 indicated that the Engineering Futures program was headed for instability: participation was shrinking and expenses were increasing. As illustrated in Table 1, total sessions were down $4.5 \%$ and total participants shrank more than $21 \%$ during $2015-16$ when compared to the prior year. At the same time, per-participant expenses went up $28 \%$ to $\$ 28.78$ per participant - the highest in the previous four years. When the participation numbers were analyzed further, it became apparent that too many resources were being expended on small sessions (10 or less participants) even though the EF program materials were designed to work best with groups of 15-25 participants. To address this challenge, the session scheduling process was adjusted starting in fall 2016 to facilitate pre-registration of participants. Host institutions were also asked to pay a $\$ 50$ session scheduling fee, which was fully refundable based on training attendance. These changes had an immediate, positive impact on the EF program: by 2017-18, per-participant costs were less than half of 2015-16 expenses and the program was serving more overall participants in fewer (larger) sessions, as shown in Table 1.

Table 1: Engineering Futures Summary by Academic Year, 2012-2018

\begin{tabular}{cccccc} 
Year & \# Sessions & \# Participants & Total Cost & Cost/Person & Cost/Session \\
\hline $\mathbf{2 0 1 2 - 1 3}$ & 224 & 3,228 & $\$ 76,474.35$ & $\$ 23.69$ & $\$ 341.40$ \\
$\mathbf{2 0 1 3 - 1 4}$ & 224 & 3,251 & $\$ 67,658.30$ & $\$ 20.81$ & $\$ 302.05$ \\
$\mathbf{2 0 1 4 - 1 5}$ & 231 & 3,554 & $\$ 85,748.23$ & $\$ 24.13$ & $\$ 371.20$ \\
$\mathbf{2 0 1 5 - 1 6}$ & 217 & 2,921 & $\$ 78,662.78$ & $\$ 26.93$ & $\$ 362.50$ \\
$\mathbf{2 0 1 6 - 1 7}$ & 176 & 3,677 & $\$ 62,113.01$ & $\$ 16.89$ & $\$ 352.91$ \\
$\mathbf{2 0 1 7 - 1 8}$ & 176 & 3,757 & $\$ 48,467.18$ & $\$ 12.90$ & $\$ 275.38$ \\
\hline Total & $\mathbf{1 , 2 4 8}$ & $\mathbf{2 0 , 3 8 8}$ & $\mathbf{\$ 4 1 9 , 1 2 3 . 8 5}$ & $\mathbf{\$ 2 0 . 5 6}$ & $\$ \mathbf{3 3 5 . 8 4}$
\end{tabular}

In addition to the immediate fiscal concerns, the program review during 2015-16 highlighted the need to fully replace the original EF curriculum within the next several years. The original materials were developed in the 1980s and intended to be delivered during lengthy (6-8 hour) sessions, generally held in-person on weekends with minimal technology (TV/VCR and chalkboards or flipcharts). While the basic concepts and skills of this training were still valuable, the needs of students and the available technology in classrooms had changed dramatically in the intervening decades. Some of the original materials had been adapted for shorter sessions and new technologies (PowerPoint, online delivery methods), but a wholesale revision was needed.

The DEF developed a two-part process to address the need for new curriculum. In the short term, the DEF sought partnerships with organizations that had developed open-source (free) materials that could be integrated into the EF catalog. One such opportunity was through the National Research Mentoring Network (NRMN) [15] and the Center for Improvement of Mentored Experience in Research (CIMER) [16], which have produced a number of training materials 
appropriate for STEM (science, technology, engineering, math) students and professionals. These materials include modular curriculum on research mentoring covering the following topics:

- Aligning Expectations

- Promoting Professional Development

- Maintaining Effective Communications

- Addressing Equity and Inclusion

- Assessing Understanding

- Fostering Independence

- Cultivating Ethical Behavior

- Articulating Mentoring Philosophy and Plan

These materials were used to add two new options to the EF catalog: "Entering Mentoring," which includes 8 hours of training on skills needed to develop effective mentoring relationships within the context of engineering research and practice; and "Equity, Inclusion \& Ethics," a 3-4 hour session focusing on increasing awareness of diversity and inclusion issues in engineering, and fostering ethical and responsible behaviors among engineers. These modules were piloted during the 2017-18 academic year, and were added to the regular EF catalog in the fall of 2018.

The DEF also pursued longer term (3-5 year) plans to develop new curriculum. The goal is to create a flexible suite of materials that can be adapted to different audiences, including students, academics, and engineering professionals. To this end, Tau Beta Pi partnered with Michigan State University and other regional and national training organizations to submit a proposal to the National Science Foundation to develop professional skills training for cyberinfrastructure professionals. This proposal was in response to a specific call for cyberinfrastructure training programs, and includes three years of activity: developing the curriculum; testing and revising the materials; and "training the trainers" so that the curriculum can be deployed nationally. This proposal was funded for three years, starting in November 2017, and Tau Beta Pi is serving as a testbed for pilot curriculum materials. This project will develop a modularized, flexible curriculum emphasizing interactive exercises (role playing / rehearsal, case studies, discussion). While the initial focus of the grant is on training cyberinfrastructure professionals, TBP will help extend the training program by adding additional exercises to reach broader audiences across engineering and other STEM disciplines.

The review and revision process that started in 2015, as Engineering Futures approached its $30^{\text {th }}$ anniversary, resulted in a new vision for the program moving forward:

Vision: Engineering Futures will be the source of professional skills training for engineers

To achieve this vision, TBP is focusing on the Engineering Futures program (1) providing high quality training resources; (2) being of service to the engineering profession; and (3) becoming financially secure. 


\section{Equity, Inclusion and Ethics Curriculum}

The Equity, Inclusion \& Ethics (EIE) module was adapted from the "Entering Mentoring" [17] materials developed by the National Research Mentor Network and the Center for the Improvement of Mentored Experiences in Research. EIE was pilot tested in 2017-18 by the DEF at the Association's annual Convention and by several other facilitators at sessions hosted by chapters across the country. The EIE curriculum was revised slightly based on feedback from these initial offerings, and the current version incorporates about 3 hours of activities, organized into three sections:

Section 1: Introduction: Establishing group dynamics and laying the ground rules are perhaps two of the most important steps to a successful training. Once established, these parameters help ensure participants engage in shared learning of ways to become more conscious of equity, inclusion and ethics issues as they relate to the practice of engineering.

\begin{tabular}{|c|c|}
\hline Learning Objective & Core Activities \\
\hline $\begin{array}{l}\text { 1. Learn about other members in the group and begin } \\
\text { building a learning community }\end{array}$ & 1. Introductions \\
\hline $\begin{array}{l}\text { 2. Reflect on group dynamics and ways to make the group } \\
\text { functional }\end{array}$ & $\begin{array}{l}\text { 2. Examining constructive and } \\
\text { destructive group behaviors }\end{array}$ \\
\hline 3. Establish ground rules for participation & 3. Generate ground rules \\
\hline
\end{tabular}

Section 2: Equity and Inclusion: Diversity, in many dimensions, offers both challenges and opportunities to any relationship. Learning to identify, reflect upon, learn from, and engage with diverse perspectives is essential to fostering effective relationships and vibrant intellectual environments.

\begin{tabular}{|c|c|}
\hline Learning Objective & Core Activities \\
\hline $\begin{array}{l}\text { 1. Recognize the impact of conscious and unconscious } \\
\text { assumptions, preconceptions, biases, and prejudices and } \\
\text { acquire skills to manage them }\end{array}$ & $\begin{array}{l}\text { 1. Reflect on Unconscious } \\
\text { Assumptions } \\
\text { 2. Implications of Diversity Research }\end{array}$ \\
\hline $\begin{array}{l}\text { 2. Increase understanding of equity and inclusion and their } \\
\text { influence on engineering }\end{array}$ & 3. $\quad$ Case Study (Language Barriers) \\
\hline $\begin{array}{l}\text { 3. Identify concrete strategies for learning about and } \\
\text { addressing issues of equity and inclusion }\end{array}$ & 4. Case Study (Is it OK to Ask?) \\
\hline
\end{tabular}

Section 3: Ethics. Engineers play an important role in both teaching and modeling ethical behavior. There are ethical issues centering on the underlying science - how to conduct, report, and write scientific and engineering studies - as well as relationships between engineers and their colleagues, supervisors, and the public. Reflecting upon and discussing ethical behavior is an important part of becoming an effective engineer.

\begin{tabular}{|c|c|}
\hline Learning Objective & Core Activities \\
\hline $\begin{array}{l}\text { 1. Become familiar with the code of ethics developed by } \\
\text { the Society of Professional Engineers }\end{array}$ & $\begin{array}{l}\text { 1. Review NSPE Code of Ethics for } \\
\text { Engineers }\end{array}$ \\
\hline $\begin{array}{l}\text { 2. Articulate ethical issues in engineering research and } \\
\text { practice }\end{array}$ & $\begin{array}{l}\text { 2. Case Study (Tweaking the Data) } \\
\text { 3. Case Study (Plagiarism) }\end{array}$ \\
\hline $\begin{array}{l}\text { 3. Clarify their role in practicing ethical behavior and } \\
\text { educating others about ethics }\end{array}$ & 4. Case Study (A Big, Strong Guy) \\
\hline
\end{tabular}




\section{Initial Curriculum Evaluations}

A variety of paper evaluation forms had been used over the years to gather feedback from students about their EF participation experiences. Once the curriculum was well-established, these feedback forms were used primarily to gather information about the facilitators and used as part of their ongoing training. These data were generally reviewed by the facilitators after their sessions and then discarded, with only intermittent efforts to capture data across the program.

In 2017-18, the DEF introduced a brief online evaluation form that participants were asked to fill out at the end of each training session (using their personal phones or mobile devices). 1,359 responses were received, representing $36 \%$ of participants in 2017-18. Six sessions were evaluated: four from the original curriculum (People Skills, Team Chartering, Group Process, Analytical Problem Solving); one that had been in use for more than 10 years (Effective Presentation Skills); and one that was being piloted during 2017-18 (Equity, Inclusion \& Ethics).

Participants were asked six questions, common across all sessions, and responded using a fivepoint Likert scale (Strongly Agree, Agree, Neutral, Disagree, Strongly Disagree). Students were first asked to rate their own desire to participate in the session; although we encourage voluntary participation, we often find that students attend in order to earn some external benefit (like extra credit for a course, or participation credit for their TBP student chapter), and thus may not be particularly interested in the session at first. Students were then asked about their perception of the materials, the facilitator, and whether they would recommend EF to their friends. Responses were not required, and not all facilitators remembered to offer the evaluation at every session. Thus, there is an inherent bias in the results towards those facilitators who remembered to use the evaluation tool, and those students willing to provide feedback.

As summarized in Table 2, the results were overwhelmingly positive: participants found the sessions interesting and helpful (regardless of their initial interest in the session), and the facilitators to be knowledgeable and enthusiastic. In looking at the results more closely, the People Skills session was less well-received overall. Responses left in the open-ended comment section of the evaluation form suggest that the lengthy video training involved with People Skills, which is unique among the sessions, is not always well received. Several participants expressed concern about the outdated videos (many of which were filmed in the 1980s) and about the overall length of the session. These comments align with what we have learned from informal conversations and more formal focus groups over the years: the dated clothing and now-obsolete technology featured in some of these training videos can distract some participants from the underlying lessons. However, experienced facilitators can use these videos effectively with positive feedback from participants. 
Table 2: Participant Evaluation Data from 2017-18

\begin{tabular}{|c|c|c|c|c|c|c|}
\hline & $\begin{array}{l}\text { Analytical } \\
\text { Problem } \\
\text { Solving }\end{array}$ & $\begin{array}{c}\text { Effective } \\
\text { Presentation } \\
\text { Skills }\end{array}$ & $\begin{array}{l}\text { Equity } \\
\text { and } \\
\text { Inclusion }\end{array}$ & $\begin{array}{l}\text { Group } \\
\text { Process }\end{array}$ & $\begin{array}{l}\text { People } \\
\text { Skills }\end{array}$ & $\begin{array}{c}\text { Team } \\
\text { Chartering }\end{array}$ \\
\hline \multirow[t]{2}{*}{ Total Respondents } & 346 & 262 & 55 & 173 & 385 & 138 \\
\hline & \multicolumn{6}{|c|}{ Percent answering "Strongly Agree" or "Agree" } \\
\hline $\begin{array}{l}\text { I wanted to participate } \\
\text { in this session. }\end{array}$ & $77 \%$ & $76 \%$ & $75 \%$ & $76 \%$ & $70 \%$ & $85 \%$ \\
\hline $\begin{array}{l}\text { I found the session } \\
\text { material interesting or } \\
\text { helpful. }\end{array}$ & $82 \%$ & $85 \%$ & $85 \%$ & $79 \%$ & $77 \%$ & $87 \%$ \\
\hline $\begin{array}{l}\text { The facilitator } \\
\text { explained the material } \\
\text { clearly. }\end{array}$ & $84 \%$ & $85 \%$ & $89 \%$ & $84 \%$ & $84 \%$ & $90 \%$ \\
\hline $\begin{array}{l}\text { The facilitator was } \\
\text { knowledgeable. }\end{array}$ & $86 \%$ & $85 \%$ & $93 \%$ & $84 \%$ & $84 \%$ & $90 \%$ \\
\hline $\begin{array}{l}\text { The facilitator was } \\
\text { enthusiastic. }\end{array}$ & $86 \%$ & $86 \%$ & $93 \%$ & $82 \%$ & $84 \%$ & $88 \%$ \\
\hline $\begin{array}{l}\text { I would recommend } \\
\text { Engineering Futures } \\
\text { to my friends. }\end{array}$ & $78 \%$ & $81 \%$ & $81 \%$ & $75 \%$ & $73 \%$ & $83 \%$ \\
\hline
\end{tabular}

\section{New Curriculum Development}

In fall 2018, the DEF piloted a new module on "Mastering Complex Conversations" at the annual Convention of the Association. This interactive training session took place in the context of complex, technical conversations and engineering projects, and led participants through exercises where they took on the roles of both speaker and listener. Participants were introduced to three tools that can be used when you are the "speaker" initiating a conversation about a complex topic: reducing jargon, using good analogies, and checking for understanding. Each of these strategies was defined and specific guidelines were offered for how to implement it during conversations. Then, the participants were divided into small groups to practice the "speaker" role. Each group had a speaker, who was supposed to practice the tools that had just been learned; an "actor" who was given specific guideline for how to respond in each scenario; and one or more coaches, whose task was to guide both participants through the exercise and encourage the proper application of the speaker techniques.

In the second part of the session, three tools for the "listener" role were introduced: reflective (or active) listening; paraphrasing; and the use of clarifying questions. Again, each tool was detailed in the context of complex, technical conversations and examples were used to explain how to apply each technique. Another series of rehearsal exercises followed, this time with the engineer serving in the "listener" role and the actor initiating the scenario, with coaches assisting both parties and providing feedback at the end.

25 participants took part in this pilot session, and all were invited to provide feedback using an online, anonymous form. 11 chose to participate, and responded to a variety of questions using a five-point Likert scale. 100\% of respondents agreed that the topic was relevant to their daily work/study, and expressed satisfaction with this effective communications module. Participants 
were also asked to rate their abilities in several areas before and after the training, as detailed in Table 3.

Table 3: "Mastering Complex Communications" Pilot Evaluation Data

\begin{tabular}{|c|c|c|c|}
\hline How would you rate your ability to... & $\begin{array}{c}\text { Average } \\
\text { Before } \\
\text { Training }\end{array}$ & $\begin{array}{c}\text { Average } \\
\text { After } \\
\text { Training }\end{array}$ & Difference \\
\hline ...communicate clearly in a variety of contexts & 3.55 & 4.09 & $11 \%$ \\
\hline ...listen actively & 3.55 & 4.09 & $11 \%$ \\
\hline ...provide constructive feedback & 3.09 & 4.00 & $18 \%$ \\
\hline ...understand jargon & 2.91 & 4.09 & $24 \%$ \\
\hline $\begin{array}{l}\text {...identify and accommodate different } \\
\text { communication styles }\end{array}$ & 2.91 & 3.91 & $20 \%$ \\
\hline $\begin{array}{l}\text {...communicate effectively with a team of peers } \\
\text { in your area of expertise? }\end{array}$ & 3.45 & 3.91 & $9 \%$ \\
\hline $\begin{array}{l}\text {..communicate effectively with a team of peers } \\
\text { with a different area of expertise? }\end{array}$ & 3.18 & 3.82 & $13 \%$ \\
\hline
\end{tabular}

While this is a small sample from a single pilot trial, the feedback suggests that the new curriculum content is valuable and the activities are structured in a way that helps participants gain knowledge and confidence. The pilot testing process for the "Mastering Complex Conversations" module and other new curricula is ongoing during 2018-19, with larger scale deployment expected starting in fall 2019.

\section{Future Work}

As part of the NSF-funded collaboration between Tau Beta Pi, Michigan State University, and several national training organizations, several hours of new professional skills training are being developed with a specific focus on leadership in engineering contexts. This training will introduce participants to common leadership styles [18], [19] and discuss methods for understanding and leading individuals with different of personality styles [20] and communication preferences [62], [63]. Participants will also have the opportunity to develop leadership skills to assist with managing competing goals and resolving conflicts between team members [21]-[23]. Leadership through mentoring [17], [24], [25] will also be a key focus, particularly as it relates to working in diverse, interdisciplinary teams [26]-[29] and as part of the leader-mentor-learner triad [30]-[32]. As with all EF training, these leadership skills will be presented using a variety of role-playing and discussion exercises to allow participants to immediately practice new skills in the context of engineering research and practice.

In addition to the materials being developed by Tau Beta Pi and Michigan State University through the NSF-funded project, the EF facilitators are lending their professional expertise to the development of additional curriculum modules. For example, a module on Design Thinking is being developed based on work done at The Pennsylvania State University. The development of this module responds to the recent growth in popularity of design thinking in both research and practice [33]. In general, design thinking is an approach to creative problem-solving. More specifically, it is a human-centered design process that emphasizes a deep, empathic understanding of user needs, creative idea generation, and an iterative approach to prototyping and testing [34]. This topic is particularly appropriate for Engineering Futures because there is a 
growing body of literature relating design thinking to engineering [35]. However, design thinking has been used in a variety of domains outside of engineering as well [36]-[38], giving promise of its potential utility for students regardless of career path. This new EF module on Design Thinking will have a target length of approximately 3 hours and programming will alternate between interactive content delivery and team-based work periods. Session participants will apply design thinking to a narrowly-scoped project, guided by one or more facilitators.

\section{Acknowledgements}

The authors wish to thank T.J. Nguyen for his work on the CyberAmbassadors project; the volunteers and staff members of TBP who make the EF program possible; and our partners at the National Research Mentoring Network (NRMN) and the Center for the Improvement of Mentored Experiences in Research (CIMER). This material is based upon work supported by the National Science Foundation under Grant No. 1730137. Any opinions, findings, and conclusions or recommendations expressed in this material are those of the author(s) and do not necessarily reflect the views of the National Science Foundation.

\section{References}

[1] J. P. Davis and K. M. Eisenhardt, "Rotating Leadership and Collaborative Innovation: Recombination Processes in Symbiotic Relationships," Administrative Science Quarterly, vol. 56, no. 2, pp. 159-201, Jun. 2011.

[2] J. Ramazani and G. Jergeas, "Project managers and the journey from good to great: The benefits of investment in project management training and education," International Journal of Project Management, vol. 33, no. 1, pp. 41-52, Jan. 2015.

[3] L. H. Lynn and H. Salzman, “Collaborative Advantage: Globalization of Innovation and Engineering," Social Science Research Network, Rochester, NY, SSRN Scholarly Paper ID 894348, Apr. 2006.

[4] Read “The Engineer of 2020: Visions of Engineering in the New Century” at NAP.edu. .

[5] C. Rottmann, R. Sacks, and D. Reeve, "Engineering leadership: Grounding leadership theory in engineers' professional identities,” Leadership, vol. 11, no. 3, pp. 351-373, Aug. 2015.

[6] W. J. Schell and B. E. Hughes, "The Potential of the Leadership Identity Model to Develop Undergraduate Engineering Leadership-A Theoretical Approach," in ASEM International Annual Conference, Charlotte, NC, 2016.

[7] “ARE ENGINEERS' LEADERSHIP ATTITUDES AND EXPERIENCES DIFFERENT THAN OTHER STUDENTS? - ProQuest.” [Online]. Available: https://search.proquest.com/openview/d772f5129fccb7b40ae014046a13f1f1/1?pqorigsite $=$ gscholar\&cbl=2037614. [Accessed: 03-Feb-2019].

[8] P. MacIntyre, “Advancing Leaders in Engineering: Ways of Learning Leadership,” Transformative Dialogues: Teaching \& Learning Journal, vol. 8, no. 3, pp. 1-18, Jan. 2016.

[9] B. Hartmann and C. Jahren, "Leadership: industry needs for entry-level engineering positions," Journal of STEM Education, vol. 16, no. 3, Sep. 2015.

[10] K. Duliba and W. N. Felder, "Strengthening Systems Engineering Leadership Curricula Using CompetencyBased Assessment," in Disciplinary Convergence in Systems Engineering Research, 2018, pp. 1121-1133.

[11] "About Tau Beta Pi." [Online]. Available: https://www.tbp.org/about.cfm. [Accessed: 03-Feb-2019].

[12] J. R. Luchini, "What Mother Never Told You About Engineering Futures," The Bent of Tau Beta Pi, no. Winter, pp. 14-18, 2014.

[13] K. Patterson, J. Grenny, R. McMillan, and A. Switzler, Crucial Conversations: Tools for Talking When Stakes Are High, Second Edition. McGraww Hill, 2012.

[14] P. Sageev and C. J. Romanowski, “A Message from Recent Engineering Graduates in the Workplace: Results of a Survey on Technical Communication Skills," Journal of Engineering Education, vol. 90, no. 4, pp. 685693, 2001. 
[15] “About the National Research Mentoring Network (NRMN) - NRMNet.” [Online]. Available: https://nrmnet.net/about-nrmn-2/. [Accessed: 17-Feb-2019].

[16] “CIMER.” [Online]. Available: https://cimerproject.org/\#/services/training. [Accessed: 17-Feb-2019].

[17] J. Handelsman, C. Pfund, S. Miller Lauffer, C. Maidl Pribbenow, and others, "Entering mentoring: a seminar to train a new generation of scientists," Ethics in Science and Engineering National Clearinghouse, p. 164, 2005.

[18] P. McCauley, Essentials of Engineering Leadership and Innovation. CRC Press, 2017.

[19] M. C. Bligh, "Leadership and Trust," in Leadership Today, J. Marques and S. Dhiman, Eds. Springer International Publishing, 2017, pp. 21-42.

[20] "The Myers \& Briggs Foundation - MBTI ${ }^{\circledR}$ Basics.” [Online]. Available: http://www.myersbriggs.org/mymbti-personality-type/mbti-basics/. [Accessed: 16-Jan-2017].

[21] E. Norris, "Managing Conflict in a Time Critical Environment—A Neglected Non-Technical Skill," Open Journal of Applied Sciences, vol. 6, no. 2, pp. 123-130, Jan. 2016.

[22] M. A. Maltarich, M. Kukenberger, G. Reilly, and J. Mathieu, "Conflict in Teams: Modeling Early and Late Conflict States and the Interactive Effects of Conflict Processes," Group \& Organization Management, p. 1059601116681127, Dec. 2016.

[23] K. Behfar, R. Friedman, and J. Brett, "Managing Co-occurring Conflicts in Teams," Group Decis Negot, vol. 25, no. 3, pp. 501-536, May 2016.

[24] M. Gandhi and M. Johnson, "Creating More Effective Mentors: Mentoring the Mentor," AIDS Behav, vol. 20, no. 2, pp. 294-303, Sep. 2016.

[25] "Macmillan Higher Education: Entering Research: A Facilitator's Manual by Janet L. Branchaw; Christine Pfund; Raelyn Rediske." [Online]. Available:

http://www.macmillanhighered.com/Catalog/product/enteringresearchafacilitatorsmanual-branchaw. [Accessed: 16-Oct-2015].

[26] T. D. Allen and L. T. Eby, The Blackwell Handbook of Mentoring: A Multiple Perspectives Approach. John Wiley \& Sons, 2011.

[27] R. Bouncken, A. Brem, and S. Kraus, "Multi-cultural teams as sources for creativity and innovation: the role of cultural diversity on team performance," Int. J. Innov. Mgt., vol. 20, no. 01, p. 1650012, Jun. 2015.

[28] R. A. Oberhelman et al., "Interdisciplinary Postdoctoral Training in Global Health Through a Novel Joint Project for Trainees from Diverse Disciplines: Benefits, Risks, and Observations," Am J Trop Med Hyg, pp. 16-0402, Nov. 2016.

[29] Y. Bai, L. Lin, and P. P. Li, "How to enable employee creativity in a team context: A cross-level mediating process of transformational leadership," Journal of Business Research, vol. 69, no. 9, pp. 3240-3250, Sep. 2016.

[30] D. A. Abrahams and C. Caldwell, "The Leader-Mentor-Learner Role of Faculty in Business Student Education," International Business and Management, vol. 12, no. 3, pp. 1-8, Jun. 2016.

[31] G. E. Søreide, "High-skilled newcomers' identity: learners or experts?," Journal of Workplace Learning, vol. 28, no. 1, pp. 2-16, Jan. 2016.

[32] H. Fehring and S. Rodrigues, Teaching, Coaching and Mentoring Adult Learners: Lessons for professionalism and partnership. Routledge, 2016.

[33] "Design Thinking: Past, Present and Possible Futures | Assist. Prof. Dr. Mehveş Çetinkaya Şendaş Academia.edu." [Online]. Available: https://www.academia.edu/11617520/Design_Thinking_Past_Present_and_Possible_Futures. [Accessed: 03Feb-2019].

[34] "What is Design Thinking?," IDEO U. [Online]. Available: https://www.ideou.com/blogs/inspiration/what-isdesign-thinking. [Accessed: 03-Feb-2019].

[35] "Engineering Design Thinking, Teaching, and Learning - Dym - 2005 - Journal of Engineering Education Wiley Online Library." [Online]. Available: https://onlinelibrary.wiley.com/doi/abs/10.1002/j.21689830.2005.tb00832.x. [Accessed: 03-Feb-2019].

[36] R. I. Clarke and S. Bell, "Chapter 14: Transitioning from the MLS to the MLD: Integrating Design Thinking and Philosophy into Library and Information Science Education," in Re-envisioning the MLS: Perspectives on the Future of Library and Information Science Education, vol. 44A, 0 vols., Emerald Publishing Limited, 2018, pp. 195-214.

[37] D. Dunne and R. Martin, "Design Thinking and How It Will Change Management Education: An Interview and Discussion," Academy of Management Learning \& Education, vol. 5, no. 4, pp. 512-523, Dec. 2006.

[38] T. W. Brown Jocelyn, "Design Thinking for Social Innovation," Development Outreach, vol. 12, no. 1, pp. 29 43, Jul. 2010. 